\title{
THE TEXTUAL FUNCTIONS OF TIME ADVERBIAL CLAUSES IN THAI TRAVELOGUES
}

\author{
Somsonge Burusphat ${ }^{1}$
}

\begin{abstract}
This article discusses the forms and textual functions of time adverbial clauses in Thai travelogue discourse. The time adverbial clauses are characterized by subordinating morphemes and word order. There are six functions of the time adverbial clauses. The first function is to maintain the journey perspective of the travelogue. The next function is to link paragraphs and sentences. The time adverbial clauses further function to background a happening in prior-time, point coincidence, continuous-punctiliar overlap, and preview. They also report the climactic outcome of the paragraph and signal the storyline. Finally the time adverbial clauses are used for temporal setting.
\end{abstract}

\section{Introduction}

This paper ${ }^{2}$ studies the forms and textual functions of time adverbial clauses found in

\footnotetext{
${ }^{1}$ Professor, Institute of Language and Culture for Rural Development, Mahidol University.

${ }^{2}$ I am grateful to Robert E. Longacre for his valuable comments and suggestions on an earlier draft of this paper and for sharing his knowledge of discourse grammar. I also thank Teun A. van Dijk for his insightful remark on the final draft of the paper. This paper was presented at the $1^{\text {st }}$ National Conference on Language, Society and Communication:
}

thirty-three travelogues in the Thai language. The travelogues were written by fourteen authors and published in twelve volumes of the Magazine of the Tourist Authority of Thailand in the past decade (1995-2004).

Travelogues are classified as narratives because they possess the features posited by Longacre, as follows:

To begin with, we can classify all possible discourses in all languages according to two basic etic parameters: contingent temporal succession and agent orientation. Contingent temporal succession (henceforth contingent succession) refers to a framework of temporal succession in which some (often most) of the events or doings are contingent on previous events or doings. Agent orientation refers to orientation towards agents with at least a partial identity of agent reference running through the discourse. (1996:8)

Pragmatics, Sociolinguistics and Discourse Studies, Chulalongkorn University, Bangkok, Thailand, July 29, 2004. 
By "contingent temporal succession," it means that narrative develops along a chronological theme-line, i.e., time line. This main line of development is termed "storyline." The travelogues are narrative as the authors narrate the activities, events, and happenings taken place during a typical journey through various regions and towns. These activities, events, and happenings that have are reported in chronological sequence. Interwoven with the narration is descriptive material that depicts scenery and people encountered along the way. Travelogues are distinguished from other types of narrative because they are narrated as if one were on a guided tour through the regions and towns and the temporal development of travelogues is essentially marked by time adverbial clauses.

Syntactically, main clauses are used to encode the storyline. The main clause as carrier of the storyline in another type of Thai narrative, i.e., folktales, has been studied extensively for some time now (Burusphat, 1991). The frequent occurrences of time adverbial clauses in Thai travelogues suggest that they play an important role in this narrative type. However, there has been no previous research on time adverbial clauses in Thai travelogues.

\section{Salience Scheme for Narrative Discourse}

My analysis of time adverbial clauses in Thai travelogues is based on the notion of salience schemes posited for narrative discourse (Longacre, 1989). It is assumed that, in most languages, clauses that advance the storyline are distinguished from clauses that do not, and storyline clauses are accompanied by clauses which report other sorts of information and which may be ranked in order of progressive degrees of departure from the storyline. Longacre (1989: 416) posits a salience scheme for English narrative as seen in diagram 1.

The storyline band is distinguished from the rest of the bands, which consist of supportive materials called nonstoryline. The terms storyline and nonstoryline are referred to by other scholars by other names.

Grimes (1975) uses the term events to refer to storyline and nonevents to nonstoryline. Nonevents are classified as Diagram1: A salience scheme for English narrative setting, background, evaluation, and collateral. Note that the term collateral is used in the same sense as irrealis.

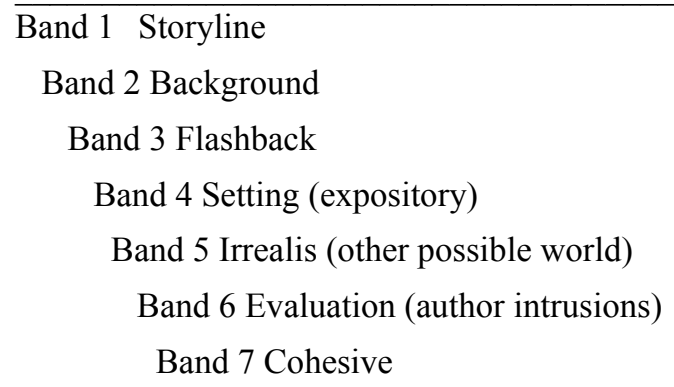

Hopper refers to the storyline as foreground, i.e., "the parts of the narrative which relate events belonging to the skeletal structure of the discourse" and the nonstoryline as background which "does not itself narrate the main events" (1979: 213).

Jones and Jones (1979) views the storyline as backbone or foreground, i.e., more significant information, and nonstoryline as background, i.e., less significant information. 
Storyline is a broad term which to includes a variety of punctiliar, sequential, and volitional happenings that advance the narrative. Punctiliar happenings include actions and events that are well articulated as to inception, terminus, or both. Sequential happenings involve a regular chronological succession of actions and events. Volitional happenings are actions that are conscious or planned.

While the highest rank of salience is assigned to storyline clauses, the clauses representing the nonstoryline (bands 2-7) can be ranked as well. Band 2 is background clauses which represent background activities and cognitive states. Background may temporally overlap with the storyline happenings or add more detail to the storyline. Background activities may be customary/routine, prolonged, repetitive, ongoing, or gradual. The next band, flashback, represents happenings which are out of the narrative sequence. The setting band consists of expository and descriptive material. It tells when and where an event takes place and also introduces participants and props. The irrealis (collateral) band includes anything that suggests possible alternatives, such as negation, questions, futures, imperatives, or predictions. Longacre notes that the irrealis band "is not part of the text world but suggests possible alternative reconstruction of that world" (1989: 418). The evaluation band is intrusive material which provides the author's own evaluation, the opinions of any participant in a discourse, the author's evaluation of the culture within which he is speaking, and the aim of the discourse expressed in the form of a moral. The final band belongs to the cohesion of various sorts. It is of the lowest rank in the scheme because it refers more to the cohesion of the story than its content.
Longacre (1989: 419-420) further asserts that the salience scheme should allow for promotion and demotion from one band to another. Punctiliar adverbs such as "suddenly" can be used to promote nonstoryline bands to storyline band as in the sentence "Suddenly he couldn't see a thing." The promotion can also be achieved by an inversion of the storyline with some other nonstoryline. The pre-posed adverbial clause can be inversed with the main clause to post-posed position and be promoted from band 7 to band 1 as in the sentence "He [the little pig] was up in the tree when he saw the wolf coming." This is true also in Thai as seen in the discussion of word order below. Demotion of an action or happening can also be made by subordinating a clause in pre-posed position, as in the sentence "When John came home he found his brother-in-law lounging in his favorite chair."

\section{Characterization of Time Adverbial Clauses}

All languages have a set of two-clause constructions in which one clause modifies the other in the same way as an adverb modifies a proposition (Thompson and Longacre, 1985). Adverbial clauses are subordinate clauses which function as modifiers of verb phrases or entire propositions. They can be divided into two groups, that is, clauses substitutable for by a single word and clauses not substitutable for by a single word. Time adverbial clauses fall into the former group. The semantic relationship between the adverbial clause and the main clause is the same as that between the adverbial word and the main clause as in (1). 


\section{Adverbial word}

(1)

\begin{tabular}{lll} 
klaaNwan & wan & $n a \Leftrightarrow n$ \\
\hline noon & day & that
\end{tabular}

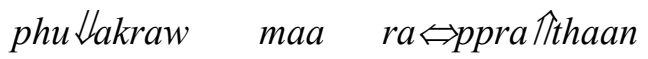

group of us come eat

klaaNwan kan thi $\downarrow$ i

$\operatorname{rooNr} \Theta \Theta m$
lunch

$k \square \square t h \square \square N$

Kawthong

'At noon that day, we went to have lunch at Kawthong Hotel.'

\section{Adverbial clause}

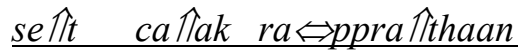

finish from eat

laa-ha®an $l \Theta \Leftrightarrow \Theta w$ phuฟak raw $k \square \downarrow \downarrow \square$

food already group we then

thay $\square \square y \quad k a n \quad$ pay

$\operatorname{ch} \square \downarrow$ ppi $\downarrow N$

go one by one together go shopping

$t \square \Uparrow \square$

continue

'(After we) had finished eating, we went on to shopping.'

Time adverbial clauses are temporal sequence clauses which signal consecutivity or succession relative to the main clause. They are used to express one event in such a sequence and marked by two devices, i.e., subordinating morphemes and word order.

\section{Subordinating Morphemes}

The time adverbial clauses are marked by grammatical morphemes with lexical content which signal temporal relationships between clauses. These subordinating morphemes function to classify time adverbial clauses into various types. They can be described in terms of a range of semantic links between two adjacent clauses. Givo $\Leftrightarrow$ n (1990) exemplifies some of the most common temporal links, which specify the temporal relation of time adverbial clause to its main clause, e.g., precedence (before), subsequence (after), simultaneity (while), point coincidence (as), and terminal boundary (till). The subordinating morphemes in Thai travelogues which serve as temporal links between the time adverbial clause and main clause are as follows:

a. Precedence: $k \square \Uparrow \square n$ 'before'

b. Subsequence: $m \propto \Downarrow$ ' 'when' $p h \square \square$ 'when' khra $\Leftrightarrow n$ 'when' weelaa 'when' la $\diamond N c a$ Tlak 'after'

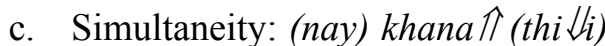
'while' (nay) $r a \Leftrightarrow w a \Uparrow \prod N$ (thi $\downarrow_{i}$ ) 'while'

d. Point coincidence: thanthiithi $\downarrow_{i}$ 'as soon as'

e. Terminal boundary: con (kra Îtha $\Downarrow_{N}$ ) 'until'

The subordinating morpheme naykhana Tthi $\downarrow_{i} i$ 'while' can be shortened to khana $\Uparrow$ thi $\downarrow$ li and khana $\uparrow$. In a similar way, the subordinating morpheme nayra $\Leftrightarrow w a \Uparrow a N$ thi $\downarrow_{i}$ 'while' also appears as nayra $\Leftrightarrow w a \Uparrow a N \quad r a \Leftrightarrow w a \Uparrow a N$ thi $\downarrow$ il $r a \Leftrightarrow w a \Uparrow a N$. 
The typical introducer of adverbial clauses is motla 'when' which is the most statistically prominent in the travelogues. Its occurrences can be compared with the occurrences of other subordinating morphemes in pre-posed and post-posed time adverbial clause as seen in Table 1 .

Even though most of the pre-posed time adverbial clauses are introduced by subordinating morphemes, it has been found that the subsequence links are often left out. These links are absent when the temporal sequence is not focused as in example (1) above, se tit ca tak $r a \Leftrightarrow$ ppra Tthaan laaha\an $l \Theta \Leftrightarrow \Theta w$ '(After we) had finished eating' and example (2)

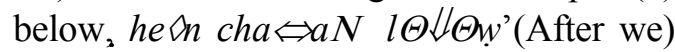
had seen the elephants'.

table 1: The occurrences of subordinating morphemes in pre-posed and post-posed time adverbial clauses

\begin{tabular}{|c|c|c|c|}
\hline \multirow[t]{2}{*}{ Subordinating morphemes } & \multicolumn{2}{|c|}{ Positional occurrences } & \multirow{2}{*}{$\begin{array}{c}\text { Total } \\
\text { occurrences }\end{array}$} \\
\hline & Pre-posed & Post-posed & \\
\hline $\begin{array}{l}\text { Subsequence } \\
m \propto \Downarrow a \text { 'when' }\end{array}$ & 66 & 56 & 122 \\
\hline la $\diamond$ Nca $\Uparrow a k$ 'after' & 28 & 8 & 36 \\
\hline zero morpheme & 28 & - & 28 \\
\hline ph $\square \square$ 'when' & 18 & - & 18 \\
\hline$k h r a \Leftrightarrow n$ 'when' & 2 & - & 2 \\
\hline weelaa 'when' & - & 1 & 1 \\
\hline $\begin{array}{l}\text { Precedence } \\
k \square \Uparrow \square n \text { 'before' }\end{array}$ & 18 & 47 & 65 \\
\hline $\begin{array}{l}\text { Simultaneity } \\
\left.\text { (nay) khana } \prod_{(\text {thi }} \Downarrow_{i}\right) \text { 'while' } \\
\text { (nay) } r a \Leftrightarrow w a \Uparrow a N\left(\text { thi } \Downarrow_{i}\right) \text { 'while' }\end{array}$ & $\begin{array}{l}10 \\
8\end{array}$ & $\begin{array}{l}19 \\
3 \\
\end{array}$ & $\begin{array}{l}29 \\
11 \\
\end{array}$ \\
\hline $\begin{array}{l}\text { Terminal Boundary } \\
\left.\text { con (kra Îtha } \Downarrow_{N}\right) \text { 'until' }\end{array}$ & 4 & 10 & 14 \\
\hline $\begin{array}{c}\text { Point Coincidence } \\
\text { thanthiithi } \Downarrow_{i} \text { 'as soon as' }\end{array}$ & 2 & 1 & 3 \\
\hline
\end{tabular}

(2)

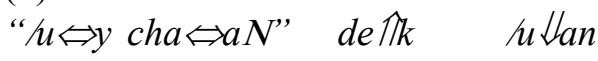

$$
\begin{aligned}
& r \square \Leftrightarrow \square N \\
& \text { Wow elephant child fat cry }
\end{aligned}
$$

thaaN daฟan la $\diamond N \quad w a \Leftrightarrow t \quad$ ceedii $\mathrm{ce}$ 个t

way side back temple stupa seven

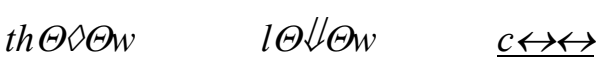
cha $\Leftrightarrow a N$

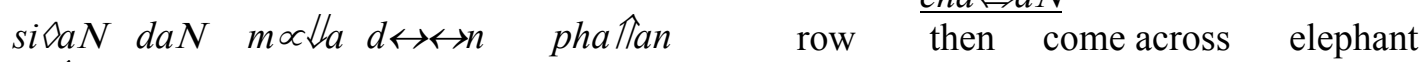

$1 \square \Uparrow \mathrm{kmaa}^{-}$

voice loud when walk pass come out 


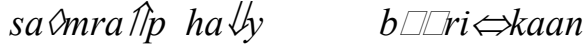

$$
\begin{aligned}
& n a \Leftrightarrow k t h \square \Downarrow N \text { thi } \Downarrow \text { aw } \\
& \text { for give service tourist }
\end{aligned}
$$

"“Wow elephant!" The fat child exclaimed loudly when he walked out in the back of Jedijetthaew Temple and came across

\begin{tabular}{|c|c|c|c|c|}
\hline \multicolumn{5}{|c|}{ 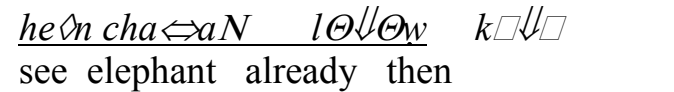 } \\
\hline \multicolumn{2}{|c|}{$\begin{array}{l}n \propto \Leftrightarrow k k h \propto \Downarrow \text { lnda } \Downarrow a y \\
c \propto N \quad d \leftrightarrow \leftrightarrow n\end{array}$} & \multicolumn{2}{|c|}{ phuฟak } & raw \\
\hline $\begin{array}{l}c \propto N \quad d \leftrightarrow \leftrightarrow n \\
\text { recall suddenly } \\
\text { walk }\end{array}$ & group & we & so & \\
\hline kha ฟam & thano:n & & pay & yang \\
\hline \multicolumn{4}{|l|}{$w a \Leftrightarrow t$} & \\
\hline cross road & go to & & aple & \\
\hline
\end{tabular}
elephants that were for tourists.'

'(After we) had seen the elephants, a thought came up to our mind. So we crossed the street to the Changlom temple.'

\section{Word Order}

The time adverbial clauses may occur in three positions, as follows:

\section{Pre-posed Position}

Because of the statistical predominance of pre-posed position of time adverbial clauses in Thai travelogues, the unmarked order of time adverbial clauses is preposed position. They normally precede the main clauses as in (1) and (2).

\section{Post-posed position}

The time adverbial clauses can also follow the main clauses. Givo $\Leftrightarrow \mathrm{n}$ (1990) states that if both pre-posed and post-posed adverbial clauses are allowed, the grounding properties of both clauses turn out to be quite different, that is, pre-posed adverbial clauses function as topical or backgrounded clauses since they do not narrate, but support, amplify, or comment on the narration. This statement holds true for the post-posed time adverbial clauses in Thai. When the adverbial clauses are post-posed, they will be foregrounded and thus they propel the narrative time line. The post-posed position is triggered by the following factors.

\section{a. Quotation}

When the main clause contains a quotation, main clause will in the initial position of the sentence. The post-posted adverbial clause is thus foregrounded. In example (3) the main clause has a pre-posed quotation as the object of the speech verb $b \square \Uparrow \llbracket k$ 'to tell'. The post-posed adverbial clause

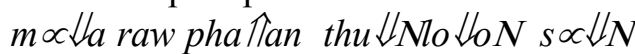
$r \leftrightarrow \downarrow_{\leftrightarrow} \rightarrow m \quad$ mii to $\downarrow$ nma $\Leftrightarrow a y \quad k h \propto \downarrow \downarrow h$ pra 1praay 'when we passed through an open field that started to have a few trees growing' is promoted to be on the storyline.

(3)

$$
\begin{aligned}
& \text { "th } \Theta \triangleright \Theta w n i \Leftrightarrow i \quad \text { pen raฟy } \\
& \text { ka } \widehat{T w} \\
& \text { area this be field old } \\
& k h \square \checkmark \square N \quad \text { phuฟlakchaawkha@w } \\
& n a \Leftrightarrow k h r a \Leftrightarrow p " \\
& \text { of group hill tribe FP }
\end{aligned}
$$

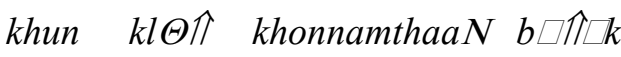

$$
\begin{aligned}
& \text { Mr. Klae guide tell }
\end{aligned}
$$




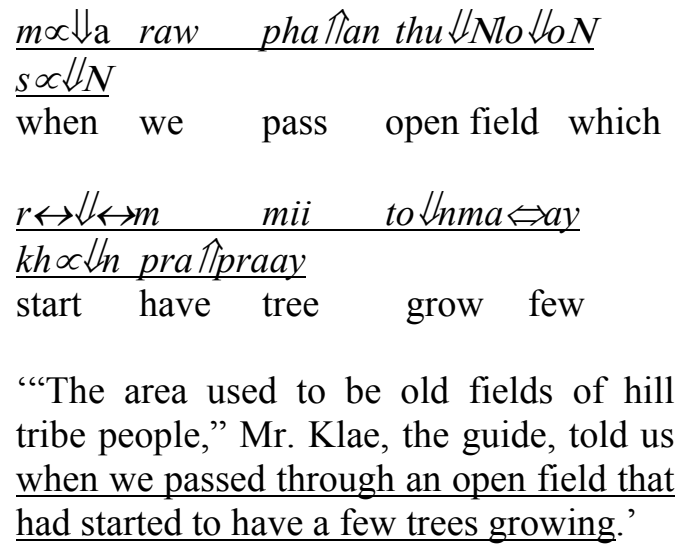

\section{b. Description}

The main clause may also be pre-posed when it reports descriptive material. The post-posed adverbial clause becomes storyline as in (4).

$$
\begin{aligned}
& \begin{array}{llc}
\text { tawan } & l a \Leftrightarrow p & k h \square \Uparrow \square p f a \Leftrightarrow a \\
\text { sun } & \text { out of sight } & \text { horizon }
\end{array} \\
& \text { pay } \quad l \Theta \Leftrightarrow \Theta w \quad \underline{m \propto \downarrow} \text { la raw } \\
& \frac{d \leftrightarrow \leftrightarrow n \text { thaaN }}{\text { go already when we travel }} \\
& \text { maa } \quad \text { th } \propto \bigotimes N \text { moaN khayfoN } \\
& \text { come arrive town Khayfong }
\end{aligned}
$$

'The sun had already set when we arrived at Khayfong town.'

However when the author aims to foreground the descriptive material encoded in an adverbial clause, this adverbial clause will be post-posed and considered as an event, as in (5).

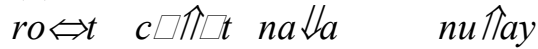

$$
\begin{aligned}
& \text { car park in front of station }
\end{aligned}
$$

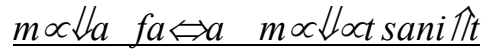 \\ when sky dark completely}

'The car parked in front of the station when the sky was completely dark.'

c. Topicality

The adverbial clause will also be postposed when its subject is different from the topical subject of the main clause. This topical subject is the same as that of the previous clauses. In example (6) the subject raw 'we' is topical. Its topicality continues from the preceding paragraph to the next paragraph in which the adverbial clause

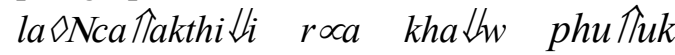
thu $\Downarrow$ ri ri lapr $\square \Leftrightarrow \square y \quad l \Theta \Leftrightarrow \Theta w$ 'after the boat was tied to the buoy' is post-posed.

(6)

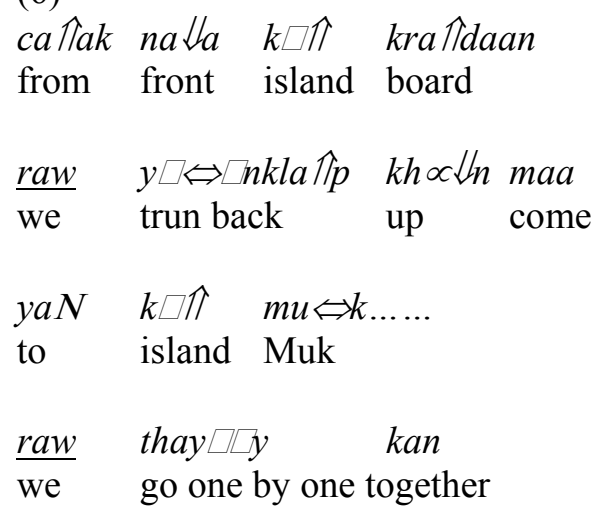

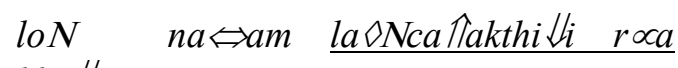
$\underline{\text { kha }}$ thw

go down water after boat enter

phuThuthuฟn riฟlapr $\square \Leftrightarrow \square y \quad l \Theta \Leftrightarrow \Theta w$

tie buoy completely already

'From the front part of Kradan island, we turned back to Muk Island.... 
We took turn going into the water after the boat was tied to the buoy.'

\section{Medial Position}

The time adverbial clauses may also occur within the main clauses when the subject of the main clauses is topicalized and preposed to the initial position of the sentence. The topicalized subject is followed by the time adverbial clauses. In example (7), the adverbial clause $m \propto{ }^{\prime}$ a phosm thi $\Leftrightarrow N$ tua

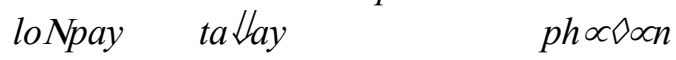
$n a \Leftrightarrow a m$ 'when I went into the deep blue water' is intervened between the topical subject sa Smpha tt $r \Theta \downarrow \Theta k$ 'the first feeling' and the rest of the main clause.

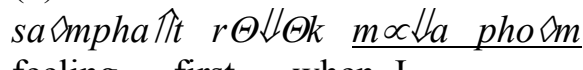
feeling first when I

thi $\Leftrightarrow N$ tua loN pay taฟay

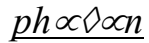

drop body down go under surface

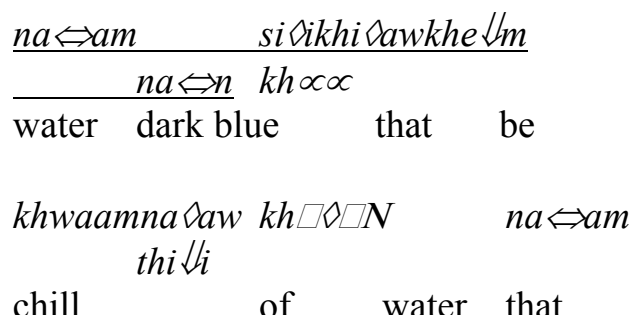

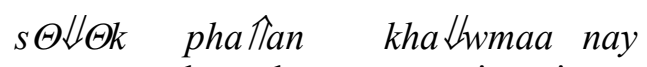
penetrate through come in in

$c h u \Leftrightarrow t w e \Leftrightarrow t s u \Leftrightarrow t \quad$ thi $\downarrow$ li mii

khwaamna $\diamond a$

suit wet suit that have thickness
tho®N 3.2 minlime Vet $k h \square \nabla \square N$ phosm

up to 3.2 millimeter of me

'The first feeling when I went into the deep blue water was the chill of the water that penetrated my 3.2 millimeter thick wet suit.'

\section{Embedded Position}

Besides the three positions mentioned above, the time adverbial clauses may also be embedded in another time adverbial clause. In example (8), the subsequent time adverbial clause motta tua sam $\square \Delta \square$ $n a \Leftrightarrow n$ loN pay th $\propto \Delta N$ ph $\propto \Leftrightarrow \propto n$ 'when the anchor hit the bottom' is embedded in another time adverbial clause $k \square \Uparrow \square n$ thi $\downarrow_{i}$ ca介 yu $\hat{\text { t }}$ loN 'before (the rope) stopped (unwinding).'

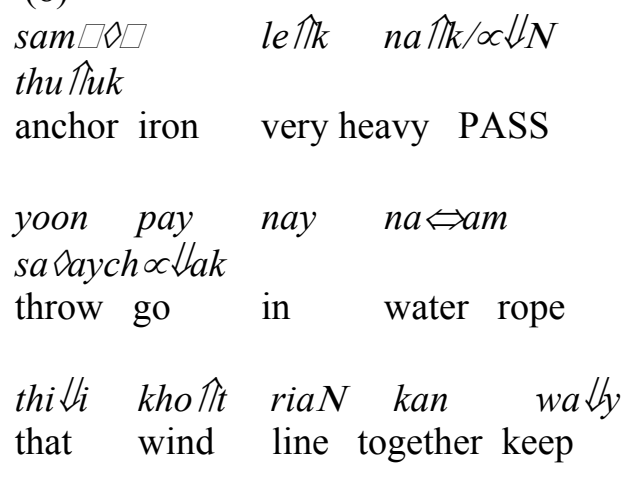

$k h \square \downarrow \downarrow \sqcup y \quad$ khlaaytua $\quad \square \Uparrow \square k$ ca Tlak kho tit gradually loosen out from coil

loN pay suth huฟaN $h \Theta \Uparrow \Theta N$

down go to backwater of

khwaaml $\propto \Leftrightarrow k \quad k \square \Uparrow \square n \quad$ thi $\downarrow$ li ca介 yu $\mathrm{Tt}$ loN 
depth before that will stop down

\begin{tabular}{|c|c|c|c|}
\hline$m \propto \triangleleft \Downarrow a$ & tua & $\operatorname{sam} \square \Delta \square$ & $n a \Leftrightarrow n$ \\
\hline & $\operatorname{loN}$ & pay & \\
\hline
\end{tabular}

$\underline{t h \propto} \bowtie N p h \propto \Leftrightarrow \Leftrightarrow \infty n$

reach bottom

'The heavy iron anchor was thrown into the water and the rope started to unwind into the depth of the water before it stopped when the anchor hit the bottom.'

The event expressed in the embedded time adverbial clause actually takes place before the event realized in the preceding time adverbial clause. All events are presented in the following chronological order.

(1) The anchor was thrown into the water.

(2) The rope started to unwind into the depth of the water.

(3) The anchor hit the bottom.

(4) The rope stopped unwinding.

\section{Functions of Time Adverbial Clauses}

\section{Maintaining Discourse Perspective}

A function of adverbial clause is "to provide cohesion for an entire discourse by assisting to maintain the discourse perspective and by helping to articulate the sections of the discourse" (Thompson and Longacre, 1985: 206).

Discourse perspective is point of view through which an event is narrated. Hopper (1995) points out that in natural discourse, events are presented from a particular perspective. In Thai travelogues events are narrated from a you're-on-a-journey perspective, which is maintained throughout the travelogues by verbs of motion in time adverbial clauses and phrases. Such clauses and phrases, therefore, function to break the travelogues into various portions. Example (9) lists a number of time adverbial clauses found in a portion of the travelogue li $\downarrow$ lap laawtallay raฟlapta Tim campaasa The

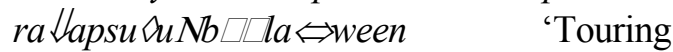
southern Laos, Jampasak lower plain, Borawen plateau'. These time adverbial clauses remind the readers of the journey perspective. Note also that all time adverbial clauses in this example have motion verbs, as underlined.

(9)

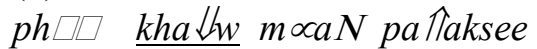
when enter town Pakse 'When (we) entered Pakse town'

$m \propto \downarrow l a \quad r o \Leftrightarrow t \quad$ li $\Leftrightarrow a w$ kha $\downarrow$ w pay

when car turn enter go

'When the car turned'

mo®la maa tho®N ta Tatfaan riis $\square \Uparrow \square t$

when come arrive Tatfan resort 'When (we) arrived at Tatfan resort'

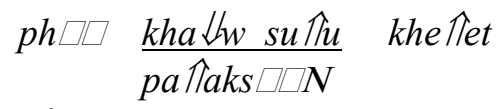
when enter to area Paksong 'When (we) entered Paksong area'

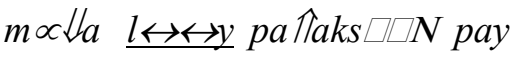

when pass Paksong go

'When (we) passed Paksong'

modla khana $\Leftrightarrow \quad$ raw maa tho®N thi $\downarrow$ li

when group our come arrive place 'When our group arrived at the place' 
$\begin{aligned} & r a \Leftrightarrow w a \Uparrow_{a} \text { Nthi } \\ & \text { pay } i \quad \text { nay while } \underline{l \Theta \downarrow_{\Theta n}} \\ & \text { boat sail go } \text { in }\end{aligned}$

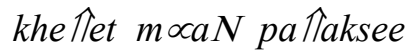

area town Pakse

'While the boat sailed into Pakse town'

\section{Linking Paragraphs and Sentences}

The time adverbial clauses may provide cohesion between successive paragraphs or within paragraphs.

\section{Cohesion between Successive Paragraphs}

The cohesive devices which are used to link successive paragraphs are tail-head linkage, head-head linkage, and summary-head linkage.

\section{a. Tail-head linkage}

The time adverbial clause may repeat the happening in the last sentence of the previous paragraph as tail-head linkage and thus it provides cohesion between paragraphs. In example (10) the time adverbial clause $p h \square \square \quad k h \propto \downarrow$ tnmaa

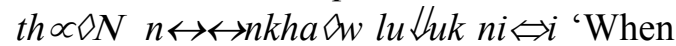
we reached this ridge' repeats the last sentence of the preceding paragraph, that

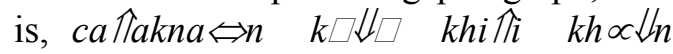
$n \leftrightarrow \leftrightarrow n \quad$ i Tikkhra $\Leftrightarrow N$ 'then rode (the bicycles) up the ridge one more time' therefore this time adverbial clause provides a linkage between two succeeding paragraphs.

$\begin{array}{lll}\text {.... cha } & \Leftrightarrow n \text { loN ca Tlak } \\ \text { laan } & \text { I get down from seat }\end{array}$

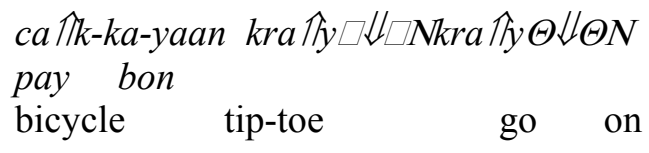

$k \square \Downarrow$ nhiin pri 个m $\quad n a \Leftrightarrow a m$

nay

rock over the surface water in

lamhuฟlay le $\Leftrightarrow k l e \Leftrightarrow k \quad c u u N$

ro $\Leftrightarrow t$

stream small lead by hands bicycle

phaakan khaฟam maa daฟay

together cross come able

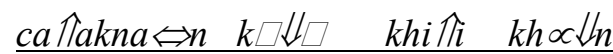
$n \leftrightarrow \leftrightarrow n$

after that then ride up ridge

îfik $k h r a \Leftrightarrow N$

more time

$p h \square \square \quad k h \propto \Downarrow_{\text {nmaa }} \quad$ th $\propto \checkmark N$
when $\quad$ come up reach

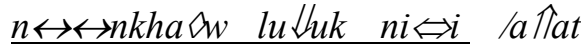

ri $\downarrow a k$

hill, ridge CLS this maybe call

daฟay waฟa raw kamlaN

khat ww

able that we in progress enter

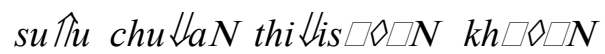

se UnthaaN

to phase second of route

$l \leftrightarrow \leftrightarrow y \quad k \square \Downarrow \square$ wa $\downarrow a \quad d a \Downarrow a y$

already also say able

'I got off the bicycle's seat, tip-toeing on stones over the surface of the small stream. (We) drew the bicycles. (We) could cross (the stream) together. After that (we) rode the bicycles to the ridge one more time. 
When (we) reached this ridge, it may be viewed that we were starting the second phase of the trip.'

\section{b. Head-Head Linkage}

A further type of linkage is head-head linkage, i.e, something mentioned in the first sentence of the preceding paragraph is referred to by means of back reference in a time adverbial clause in the following paragraph, as exemplified in example (2) above. The time adverbial clause he on $c h a \Leftrightarrow a N l \Theta \downarrow_{\Theta} \omega^{\prime}$ '(After we) had seen the elephants' repeats the first sentence of the preceding paragraph, that is, $c \leftrightarrow \leftrightarrow$ $c h a \Leftrightarrow a N^{\prime}($ we) came across elephants'.

\section{c. Summary-Head Linkage}

The first time adverbial clause of a successive paragraph may also summarize the preceding paragraph as summary-head linkage. In example (11), the underlined time adverbial clause summarizes the happenings in the previous paragraph.

$$
\begin{aligned}
& \text { thandayna } \Leftrightarrow n \begin{array}{l}
\text { khwaamchunlamun } \\
\text { suddenly chaos }
\end{array}
\end{aligned}
$$

$r a \Leftrightarrow l \square \downarrow k \quad r \Theta \downarrow \Theta k k \square \downarrow \square$

$k \leftrightarrow \Uparrow \leftrightarrow t k h \propto d \downarrow n \quad m \propto \downarrow t a$

round first then happen when

khun panya $p \leftrightarrow \Uparrow \leftrightarrow t \quad$ tha $\diamond N$

$$
\text { bay } n a \Leftrightarrow n
$$

Mr. Panya open bucket CLS that

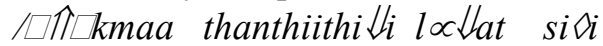

khi aaw

come out as soon as blood color green

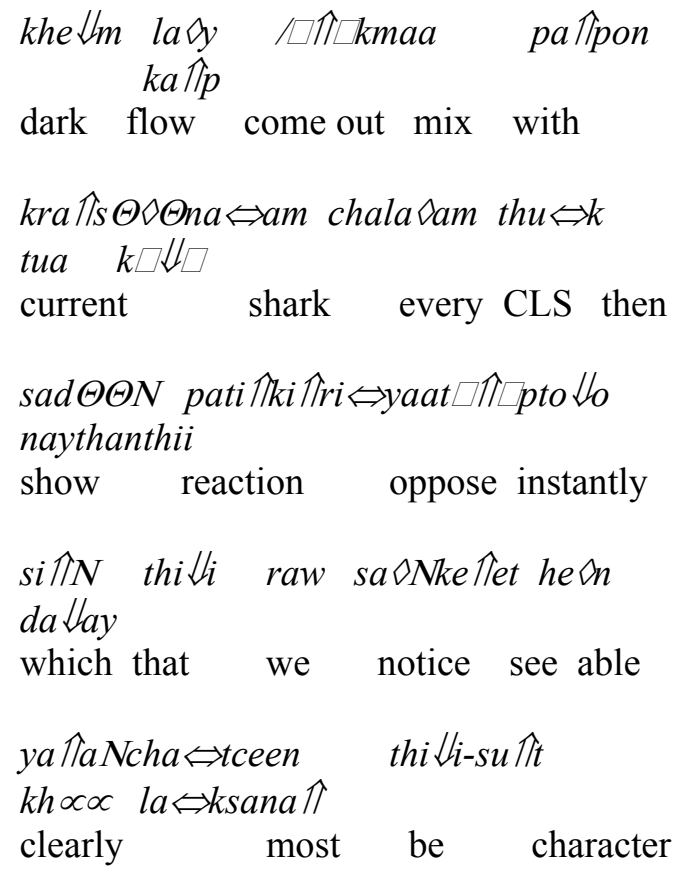

tha لathaaNnay kaanwa ฟayna $\Leftrightarrow a m$

$k h \square \nabla \square N$ man

posture in swimming of them

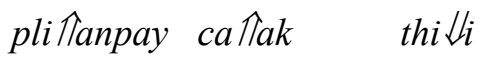

$$
k h \square \Downarrow \sqcup y k h \square \downarrow \downarrow \sqcup y \text { bo } \Uparrow o k
$$

change from that gradually wag

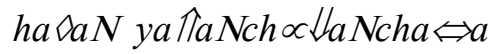

klaaypen

tail slowly become

$\begin{array}{lll}\text { laakaanlu } \Leftrightarrow k l i \Leftrightarrow i l u \Leftrightarrow k l o n & \text { khri } \\ \text { manner } & \text { hurried } & \text { fin }\end{array}$

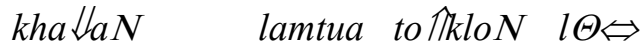

thu $\Leftrightarrow k t h u \Leftrightarrow k$

side body drop and every

tua $\quad r \leftrightarrow \forall \leftrightarrow m$ bi Tip woN

$k h \Theta \downarrow \Theta p$

CLS start force circle narrow

khaฟwmaa phr $\square \Leftrightarrow \square m p h r \square \Leftrightarrow \square m \quad k a n$ come in at the same time together 


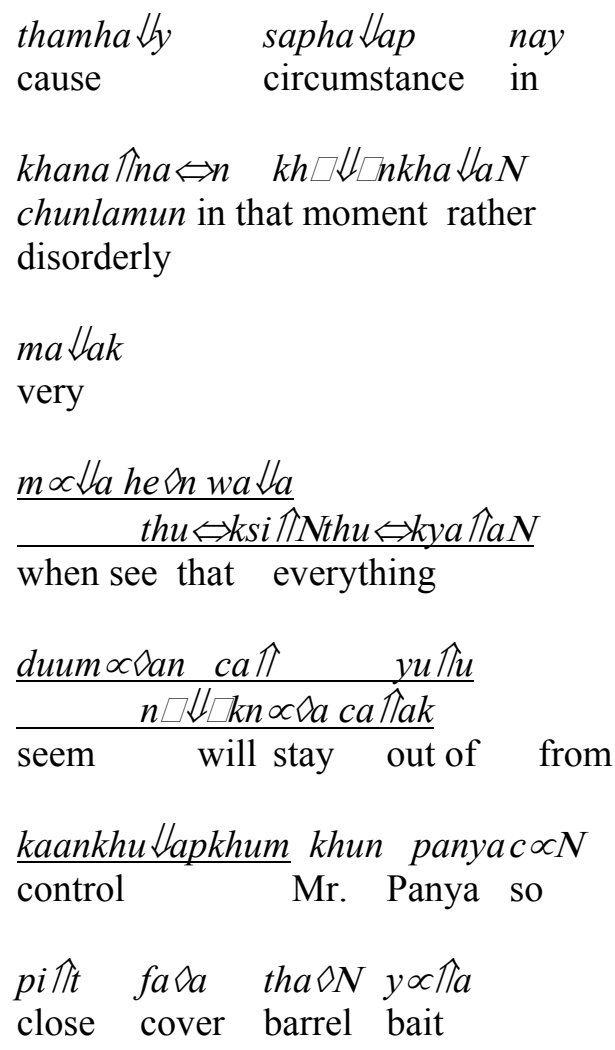

'Suddenly a first wave of chaos started when Khun Panya opened the barrel. The deep green blood spilled out of the barrel. The dark green blood spilled into the current and all the sharks reacted instantly. It could be seen that the sharks' swimming posture changed from slow motion into faster movement, with the fins dropping to their sides while moving into a narrow circle which resulted in a rather disorderly circumstance.

After Mr. Panya realized that things were getting out of control, he closed the bait barrel.'

\section{Cohesion within Paragraphs}

Time adverbial clauses are further used as intraparagraph connectives. They contain a back reference to the preceding clause. This may be a recapitulatory back reference or a script-referential back reference.

\section{a. Recapitulatory Back Reference}

Recapitulatory back reference is a repetition of the element of the preceding clause. In repeating the happening in the prior clause, the time adverbial clause provides cohesion within the paragraph. In example (12), the adverbial clause

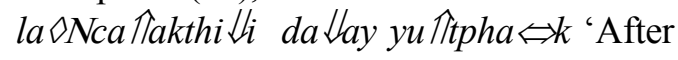
(we) had a rest' is a recapitulation of previous material, that is, yu fit kin kha \aw 'stopped for lunch'.

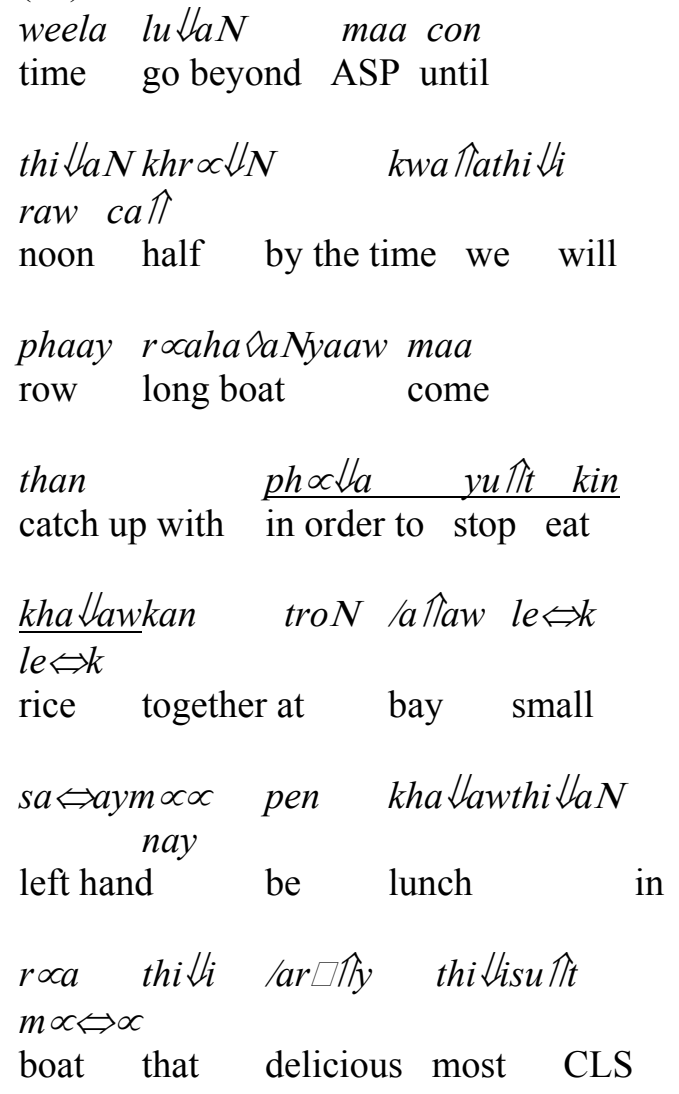




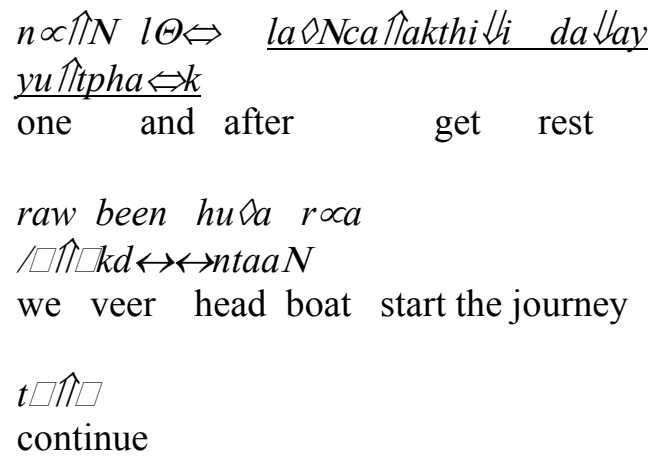

'It was well after noon before we rowed till we caught up with the long boats so that we could stop for lunch at a small bay on the left. It was one of the best luncheons in the boat for us. After we had rested, we continued with the trip.'

\section{b. Script-Referential Back Reference}

Besides a recapitulation of previous material in the travelogues, the time adverbial clause is also a back reference to a happening which has not been referred to previously but which is predictable from the preceding material. In example (13), while the first sentence reports the event 'Taking the group to a restaurant', the time adverbial clause of the second sentence mentions the next event in the eating script, that is, $\quad r a \Leftrightarrow$ ppralthaan laaha\an $l \Theta \Leftrightarrow \Theta w$ '(After we) ate lunch', which is highly predictable. This time adverbial clause is not introduced by a subordinating morpheme but tagged by the perfective marker $l \Theta \Leftrightarrow \Theta w$ 'already', which marks the completion of the previous event.

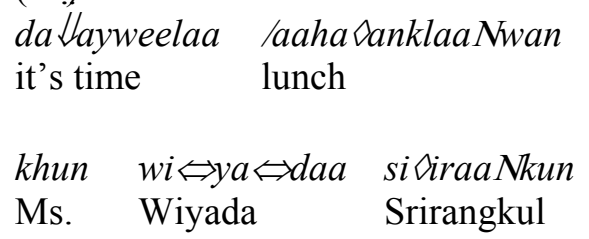

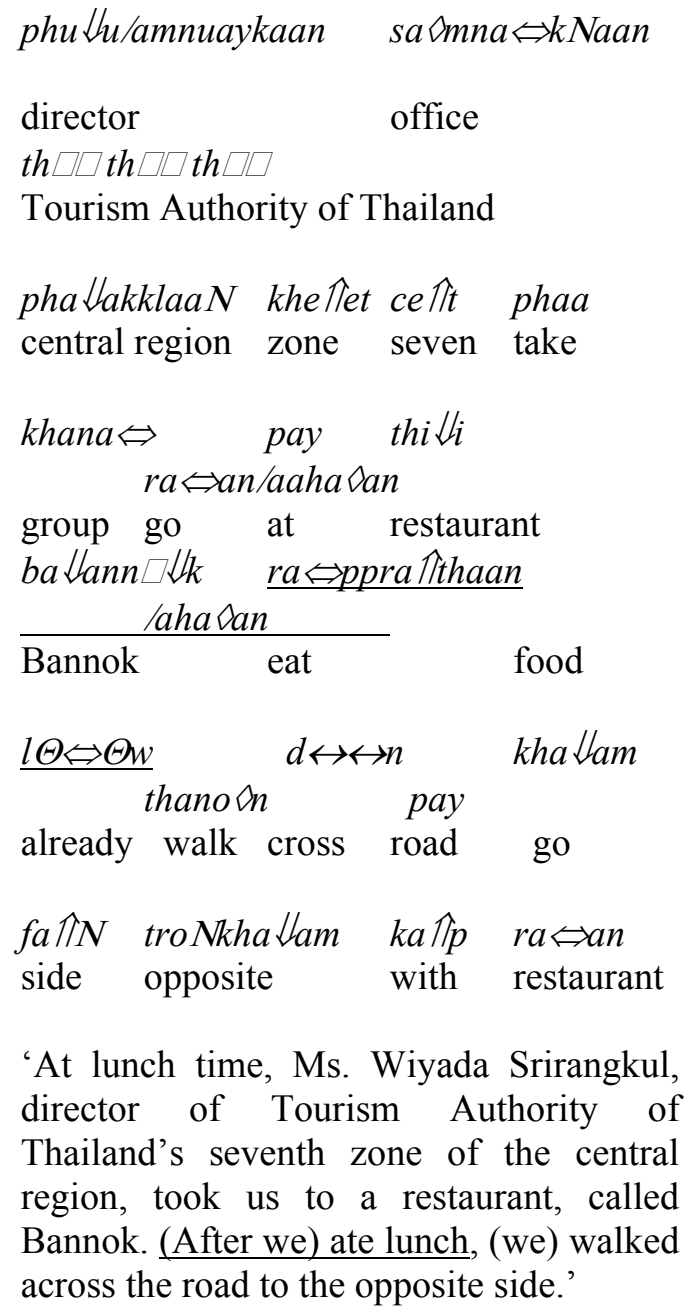

'At lunch time, Ms. Wiyada Srirangkul, director of Tourism Authority of Thailand's seventh zone of the central region, took us to a restaurant, called Bannok. (After we) ate lunch, (we) walked across the road to the opposite side.'

\section{Backgrounding a Happening}

The term GROUNDING is referred to by Hopper and Thompson as "linguistic features associated with the distinction between foreground and background" (1980: 280). The time adverbial clause can also be used as a device to demote a happening from the storyline band to the background band. The backgrounded time adverbial clause may represent prior-time, point coincidence, continuous-punctiliar overlap, and preview as discussed below. 


\section{a. Prior-time}

A happening can be made less prominent than the following happening by having the prior-time happening reported in a subordinate clause and the following happening in the main clause. In example (14), the time adverbial clause reports the

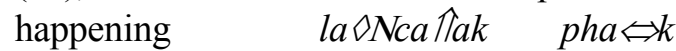

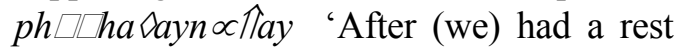
and fresh up', which is backgrounded, whereas the main clause presents the happening raw $k \square \downarrow \downarrow \square \square \backslash \backslash \backslash k d \leftrightarrow \leftrightarrow$ thaaN

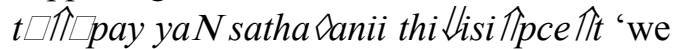
then continued on to station 17', which is on the storyline.

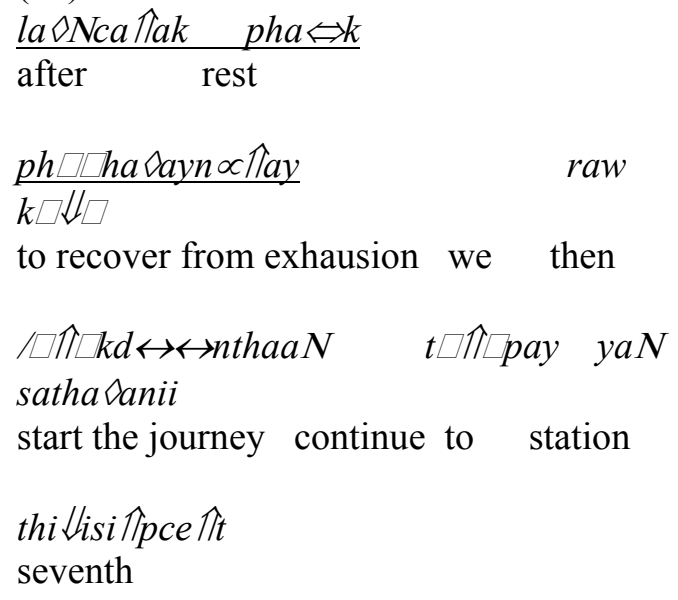

'After (we) had a rest and fresh up, we then continued on to station 17.'

\section{b. Point Coincidence}

A happening may also occur at the same time as on other happening but be less prominent than the other, so it is represented in an adverbial clause introduced by the subordinating morpheme thanthiithi $\downarrow \downarrow$ i 'as soon as'.
Example (15) has the time adverbial clause thanthiithi $\downarrow_{i}$ sa Saysam $\square \nabla \square n a \Leftrightarrow n t \propto N$ 'As soon as the anchor line was straightened', which is a happening demoted to a background happening. This demoted happening is of less prominence than the happening reported in the main clause raw

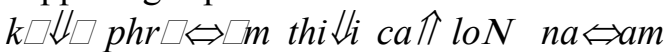
kan thanthii 'we were then ready to go down into the water right away.' Note also that the time adverbial clause has another time adverbial clause embedded in it, that

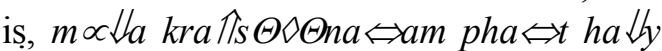
roca pay yu Thu nay thi $\Leftrightarrow$ thaaN thi $\downarrow_{i}$ man khuanca介pen 'when the current forced the ship into the proper direction.'

\begin{tabular}{lll} 
thanthiithi $\downarrow_{i}$ & sa\aysam $\square \searrow \square$ & $n a \Leftrightarrow n$ \\
\hline as soon as & anchor line & that
\end{tabular}

$t \propto N \quad m \propto \downarrow t a$

kra $\prod_{s} \Theta \diamond \Theta n a \Leftrightarrow a m$

straighten when current

\begin{tabular}{lllll}
$p h a \Leftrightarrow t$ & $h a \Downarrow y$ & $r \propto a$ & $p a y$ & $y u \Uparrow \hat{\imath}$ \\
\hline force the wave let & boat & go be
\end{tabular}

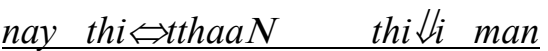

khuanca介 pen

in direction that it should be

raw $k \square \downarrow \downarrow$ phr $\square \Leftrightarrow \square m$ thi $\downarrow$ li ca介 loN

we then ready that will go down

$n a \Leftrightarrow a m \quad k a n \quad$ thanthii

water together right away

'As soon as the anchor line was straightened when the current forced the ship into the proper direction, we were then ready to go into the water right away.' 


\section{c. Continuous-Punctiliar Overlap}

A pre-posed time adverbial clause can be used to convey a background happening which is continuative and durative. This background happening overlaps with a main clause happening which is punctual and successive. Thompson and Longacre explains the continuous-punctiliar overlap as "a span of activity during which an event takes place" (1985: 216). The pre-posed time adverbial clause encoding continuative happening is introduced by the subordinating morpheme naykhana Îthi $\downarrow_{i}$ 'while' and usually has the pre-verbal progressive marker kamlaN 'in progress', as in example (16).

$\frac{\text { naykhana Tithilliphosm }}{\text { while I }}$

\begin{tabular}{|c|c|}
\hline kamlaN & khaya 1p tua \\
\hline ha\ty & \\
\hline
\end{tabular}

khaฟwpay yuThu nay mum

$\frac{\text { thi } \Downarrow_{i} i}{\text { go in be in corner that }}$

$\underline{t \square \Downarrow \square \text { Nkaan }}$ sa囚aytaa phoऽm $k \square \downarrow \downarrow$ desire sight I then

lociappayhe in

glance

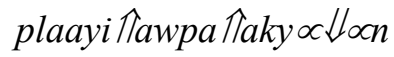

hawk fish having extended mouth

$\begin{array}{lll}\text { tîk } & \text { tua } & n \propto \Uparrow \Uparrow N \text { thi } \Downarrow_{i} \\ \text { more } & \text { CLS } & \text { one that }\end{array}$

$$
\begin{aligned}
& \text { lo Tिpmum yu } \\
& \text { hide in a corner be on cluster } \\
& \text { paTkkaaraN dam tîik daฟan } \\
& n \propto \Uparrow N \\
& \text { coral black another side one }
\end{aligned}
$$

'While I was trying to ease my body into a desirable posture, I saw another hawk fish hidden in a corner of the black coral.'

\section{d. Preview}

While the pre-posed time adverbial clauses introduced by the subordinating morphemes $m \propto{ }^{\prime} l a, p h \square \square, k h r a \Leftrightarrow n$, and la $\diamond$ Na Tlak 'when' realize happenings which take place before those in the main clauses, the time adverbial clauses introduced by $k \square \Uparrow \llbracket n$ 'before' express the happenings that have not yet occured by the time of the happenings expressed in the main clauses. The $k \square \Uparrow \llbracket n$ 'before' clauses serve as a preview of the happening that will occur after the happening named in the main clause. In expressing the preview of a happening, the clauses heighten the significance of the real happenings presented in the main clauses. Since the $k \square \Uparrow \llbracket n$ clauses have yet take place, they are marked by the preverbal irrealis marker ca $\Uparrow$ 'will'.

The $k \square \Uparrow \llbracket n$ clauses which serve as a preview normally occur in pre-posed position, as in example (17). However, they can also be post-posed when they are repeated later on as the storyline, as in example (18). In this example the postposed time adverbial clause $k \square \Uparrow \square n$ thi $\downarrow$ li ca $\Uparrow k h a \Downarrow_{w}$ thi $\downarrow_{i p h} a \Leftrightarrow k$ 'before (we) went to the lodging' is a preview which is mentioned again as a real happening on the narrative time line, that is, raw $c \propto N$ kha $\Downarrow_{w}$ thi $\Downarrow_{\text {ipha }} \Leftrightarrow k$ 'we then went to the 
lodging.' Example (18) also has the time adverbial clause setit ca介lak tha Tlaypaฟlap phra $\Leftrightarrow$ /aathi $\Leftrightarrow t$ ri $\downarrow$ lapr $\square \Leftrightarrow \square y \quad l \Theta \Leftrightarrow \Theta w$ 'After (we) had taken pictures of the sun', which repeats the previous material tha Tlay pha lap phra $\Leftrightarrow$ /aathi $\Leftrightarrow$ t to TkloN bon laanhi on 'took pictures of the sunset on the plateau' as a linkage within paragraph.

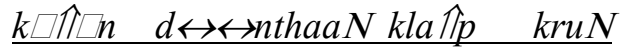

$$
\begin{aligned}
& \text { the tep } \\
& \text { before travel return Bangkok } \\
& \text { ca lak }
\end{aligned}
$$

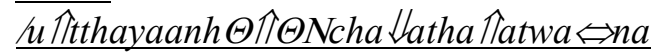

$$
\begin{aligned}
& \Leftrightarrow k \square \square n \\
& \text { from national park Wanakorn beach } \\
& \text { raw yaN } w \Theta \Leftrightarrow \quad \text { praanburii } \\
& \text { thi } \Downarrow \text { aw } \\
& \text { we also stop by Pranburi travel } \\
& w a \Leftrightarrow n a \Leftrightarrow \text { M Itthayaan } \\
& \text { national park }
\end{aligned}
$$

'Before (we) left Wanakorn beach national park for Bangkok, we also stopped by at Pranburi national park.'

$$
\begin{aligned}
& r o \Leftrightarrow t c i \Leftrightarrow p \quad \text { si \id } \Theta \Theta N \quad k h \square \nabla \square \text { Nraw } \\
& \text { jeep red our }
\end{aligned}
$$

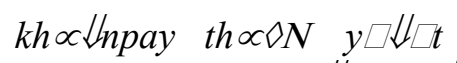

$$
\begin{aligned}
& \text { phuuhi inr } \square \downarrow \square \text { Nkla } \downarrow a \\
& \text { go up reach top rocky mountain } \\
& \text { law } \quad t \square \square n \quad d \Theta \Uparrow \Theta \text { tro } \Downarrow m l o m t o \prod_{k} \text { raw } \\
& \text { up to time near sunset we } \\
& l \leftrightarrow \leftrightarrow y w \Theta \Leftrightarrow \quad k h a \downarrow^{\prime} w \text { laanhi int } \Theta \Uparrow \Theta k
\end{aligned}
$$

so stop by enter broken rock plateau

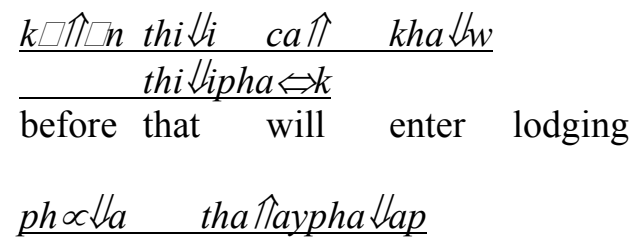

phra $\Leftrightarrow$ /aathi $\Leftrightarrow t$

in order to take picture sun

$\frac{\text { to TkloN bon laanhi on }}{k \square \downarrow \square} \quad s \propto \Downarrow_{N}$ raw

set on plateau which we then

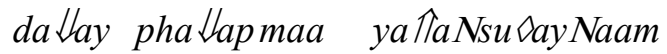

get picture ASP beautifully

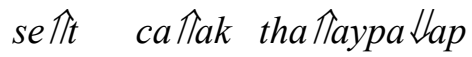

phra $\Leftrightarrow /$ aathi $\Leftrightarrow t$

finish from take picture sun

ri $\downarrow$ apr $\square \Leftrightarrow \square y l \Theta \Leftrightarrow \Theta w \quad$ raw $c \propto N$ $k h a \downarrow$ w

done already we then enter

thillipha $\Leftrightarrow k$

lodging

'Our jeep reached the top of the rocky mountain near sunset. So we stopped by at broken rock plateau before (we) went to the lodging in order to take pictures of sunset on the rocky plateau. We could take beautiful pictures. After (we) had taken pictures of the sun, we then went to our lodging.'

. In post-posed position, the $k \square \Uparrow \llbracket n$ 'before' clauses are foregrounded as storyline. They report happenings which occur in succession to the previous one, and thus, they are on the narrative time line. Example (19) has two 'before' clauses which do not represent a preview but 
occur in succession to the previous happenings and, thus, advance the storyline.

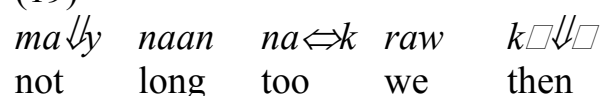

$$
\begin{aligned}
& \text { pho@ps } \Theta \triangleright \Theta N \text { sawa } \Uparrow a N \quad r \square \square \\
& \text { yu } \widehat{\text { hu }} \text { thi } \downarrow_{i} \\
& \text { see light wait be at } \\
& \text { plaaythaaN îtikdaฟann } \propto \Uparrow \uparrow \text { raw } \\
& m u \Downarrow N \\
& \text { end another side we bound } \\
& \text { for }
\end{aligned}
$$

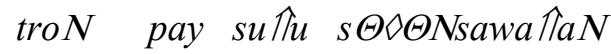

$$
\begin{aligned}
& n a \Leftrightarrow n \\
& \text { straight go to light that } \\
& \frac{k \square \Uparrow \square n \text { thi } \Downarrow_{i} \text { ca介 } \quad N \leftrightarrow \leftrightarrow y}{h u \diamond a \quad k h \propto \Downarrow \text { tnmaa }} \\
& \text { before that will raise head come up }
\end{aligned}
$$

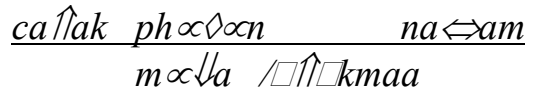

$$
\begin{aligned}
& \text { from surface water when come out } \\
& \text { phaayn } \square \downarrow \downarrow k \text { tha } \downarrow \text { m } l \Theta \Leftrightarrow \Theta w \ldots \\
& \text { outside cave already } \\
& \text { phuฟakraw th } \square \Uparrow \square t \quad \text { u介ppak } \square \square n \\
& \text { group we take off gear } \\
& \text { damna } \Leftrightarrow a m \quad / \square \Uparrow \square k \quad k \square \square N \\
& \text { lawwa } \Leftrightarrow y \\
& \text { diving out pile keep }
\end{aligned}
$$

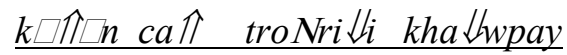

$$
\begin{aligned}
& \text { before will go straight go in } \\
& \underline{n \square \square n \quad k l i \Downarrow N k l \propto \downarrow} \Downarrow_{a k} \text { kan } \quad y u \Uparrow u \\
& \underline{b o n}
\end{aligned}
$$

lie down roll together be on

haThatsaay le $\Leftrightarrow k l e \Leftrightarrow k$ thi $\downarrow_{i} \quad s \Theta \diamond \Theta n$ saNo $\uparrow_{p}$

beach small that very tranquil

$\underline{h \Theta \Uparrow N n a \Leftrightarrow n}$

CLS that

'Soon after we saw light waiting at the other end, we went in that direction before we emerged from the water surface after we left the cave....

'We took off our diving gear before (we) we went straight to lie down on that tranquil

\begin{tabular}{|c|c|c|c|c|}
\hline car & $\begin{array}{l}\text { raw } \\
\text { run }\end{array}$ & take & group & we \\
\hline chom & ba ฟlan & chom & $m \propto a N$ & pay \\
\hline see & house & see & town & go \\
\hline & $t h \propto \diamond \Lambda$ & sana & mbin & \\
\hline
\end{tabular}
small beach.'

\section{Marking the Climactic Outcome of the Paragraph}

Time adverbial clauses introduced by the subordinating morpheme conkratha $\Downarrow_{N}$ 'until' or the shortened form con function to mark the climactic happening of the paragraph. These time adverbial clauses occur mostly in post-posed position and advance the narrative time line. It often reports an arrival at a destination.

The shortened form con is usually used to introduce this kind of time adverbial clause, and it is often followed by the motion verb. maa) th $\propto \Delta N$ 'arrive', as in example (20).

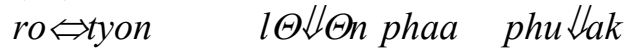


until arrive airport

'The car took us sightseeing until we reached the airport.'

conkratha $\Downarrow N$ weelaa taam
until time according to

Time adverbial clauses introduced by conkratha $\Downarrow_{N}$ 'until' also contains other types of verbs. Example (21) has the action verb pay pho $\Leftrightarrow$ p 'come across.'

pho⿰m $k h \square \downarrow \downarrow \sqcup y k h \square \downarrow \downarrow y$

$s \square \Uparrow \square$ tsa Taysa \aytaa

I slowly look around

khwaanha \a conkratha $\Downarrow_{N}$ pay

$\frac{p h o \Leftrightarrow p k a \Uparrow p}{\text { search until go meet }}$

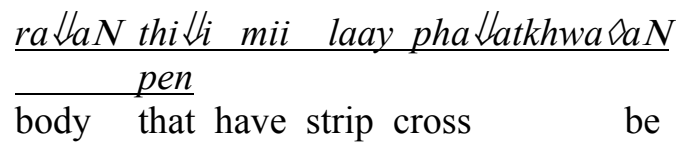

taaraaN $\quad$ laaysak $\square \Leftrightarrow t \quad k h \square \nabla \square N$
man thi $\Downarrow_{i}$

reticulation Scot pattern of it that

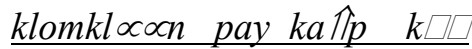

pakaaraN

blend go with cluster coral

\begin{tabular}{llll} 
dam & thi $\Downarrow_{i}$ & man & laasa@yyu $\prod_{u}$ \\
\hline black that & it & live stay
\end{tabular}

'I searched for it until (I) saw a body that had a Scot stripe that helped blend the body with the black coral in which it lived.'

In pre-posed position, the time adverbial clause serves as a background happening and is not on the storyline, as in example (22).

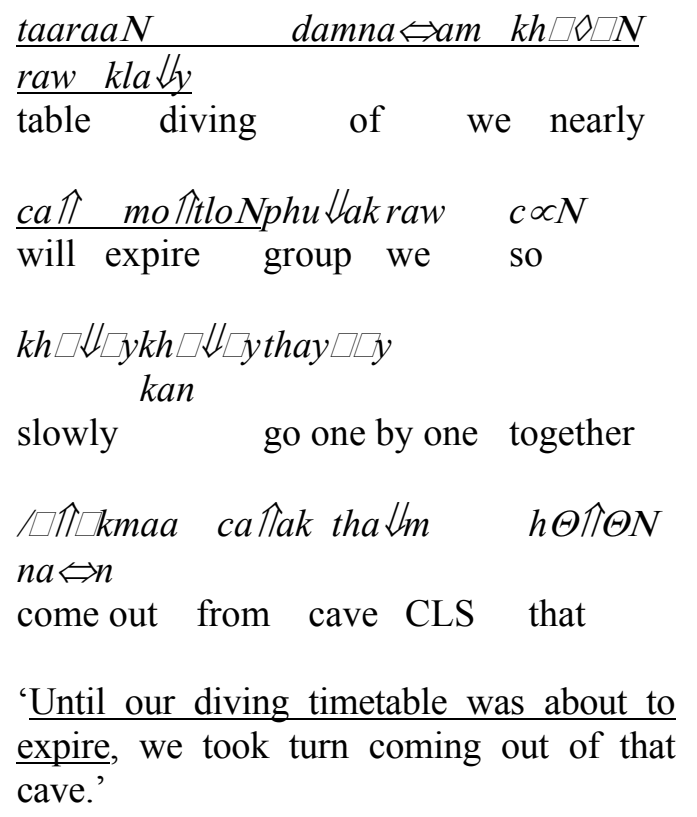

\section{Signaling Storyline}

Each language makes use of particular features to mark storyline and nonstoryline. In languages with tense-aspect systems, such as English, the verb system facilitates discourse. That is, differing tense, aspect, mood, and voice forms have different functions in discourse. In narrative discourse, for example, simple past-tense forms report successive actions and events which advance the story, whereas pastprogressive forms report concomitant activities or nonstoryline (Longacre, 1996).

Thai is a language without verbal inflection. Storyline and nonstoryline cannot, therefore, be characterized solely on the basis of verb forms as in English. Thai uses grammatical forms to mark a distinction between storyline and nonstoryline. The time 
adverbial clause is a device that is frequently used to signal the storyline, as it marks the completion of the previous happening and the beginning of the new happening which is on the storyline.

Sequentiality is a significant way in which Thai marks the difference between the storyline and nonstoryline. The happenings of a foregrounded narrative succeed one another. Hopper refers to this succession as being in iconic order, i.e., "the same order as their succession in the real world" (1979: 214-215). He also refers to foregrounded happenings as being dynamic and active. The sequentiality of foregrounded happenings requires that a happening occur after the completion of a prior event.

The sequentiality of storyline in Thai travelogues is frequently signaled by the use of time adverbial clause. The time adverbial clause is a very frequent device used to link a previous happening to a succeeding one. It signals the completion of the previous happening and the beginning of the next one. The time adverbial clause is usually tagged by the perfective marker $l \Theta \Leftrightarrow \Theta w$ 'already', which confirms the completion of a happening in the time adverbial clause and signals the beginning of a new happening in the main clause. The main clause frequently has the preverbal auxiliary $k \square \downarrow l \downarrow \square$ 'then' or $c \propto N$ 'consequently', which also marks the chronological order of happenings. Example (14) illustrates the use of the time adverbial clause la $\Delta$ Nca Tak $\quad p h a \Leftrightarrow k$

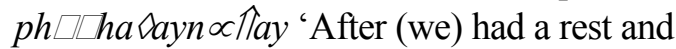
fresh up' to signal the storyline happening

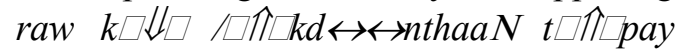
yaN satha Sanii thi لlisi Tppee It 'we then continued on to station 17.'

\section{Reporting a Temporal Setting}

A further function of time adverbial clause is to provide a temporal setting to sections of travelogues. They tells readers when an event takes place, as in example (23).

(23)

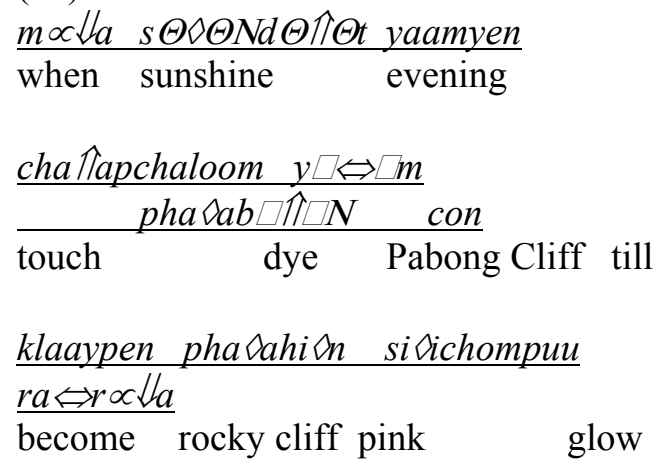

ro $\Leftrightarrow$ thit $\Theta \Leftrightarrow \Theta k \quad k \square \downarrow L$ so $\Uparrow N$ si $\ a N$

$t u \Leftrightarrow k t u \Leftrightarrow k$

Etak vehicle then blare sound of car

bantu $\Leftrightarrow k \quad$ phuฟak rawthiimNaan transport group we workteam

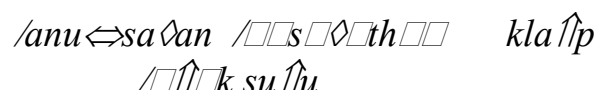

magazine TOT return go out to

suSun $b \square$ rikaan $n a \Leftrightarrow k t h \square \downarrow \downarrow$ Nthi $\Downarrow_{a w}$ center service tourist

'When the evening sun ray touched Pabong Cliff until it turned into glowing pink cliff, the Etak vehicle blared 'tuktuk' while transporting the team of the Tourism Authority of Thailand back to the tourist center.'

\section{Conclusion and Discussion}

Time adverbial clauses in Thai travelogues can be characterized by subordinating 
morphemes and word order. The typical subordinating morpheme is molla 'when'. The unmarked word order is pre-posed position. The time adverbial clauses can be post-posed when they are foregrounded.

Time adverbial clauses have six major functions:

1.They are used to maintain the journey perspective of the travelogues.

2.They function to link paragraphs with tail- head linkage, head-head linkage and summary-head linkage and to link elements within a paragraph via recapitulatory back reference and script-referential back reference.

3.They are further used to background a happening in prior-time, point coincidence, continuous-punctiliar overlap, and preview.

4.The subordinating morpheme con 'unit' . introduces the time adverbial clauses which report the climactic outcome of the paragraph.

5.Most time adverbial clauses mark the completion of the previous happening and signal the beginning of the next happening which is on the storyline.

6.Finally, time adverbial clauses are used for temporal setting.

Comparing this work to the work of Thompson and Longacre (1985), the functions of adverbial clauses delineated in both works are maintaining the discourse perspective and linking paragraphs and sentences. Backgrounding a happening is discussed under linkage via adverbial clauses in sentence margins by Thompson and Longacre. The rest of the functions are not mentioned in their work.
In other types of narrative, happenings with subject as agent and volitional actions are of the highest order in the salience scheme (Longacre, 1989). As travelogues focus on the movement of the authors as travelers from one place to another, motion verbs play a larger role in travelogues than in other types of narrative as attested by the statistical count of verb forms ${ }^{2}$ in table 2 .

table 2: The statistical count of verb forms

\begin{tabular}{|l|c|}
\hline \multicolumn{1}{|c|}{ Types of verbs } & $\begin{array}{c}\text { Percentage of } \\
\text { occurrences }\end{array}$ \\
\hline Motion & 50.64 \\
\hline Action & 29.80 \\
\hline Perception & 6.08 \\
\hline Cognition & 5.44 \\
\hline Description & 4.80 \\
\hline Contingencies & 3.20 \\
\hline
\end{tabular}

Based on the dominant characteristics of the verb forms, the time adverbial clauses can be ranked as in diagram 2 .

\footnotetext{
${ }^{2}$ Motion verbs have the subject as both agent and patient; when the subject goes somewhere $\mathrm{s} /$ he moves her/himself in that direction. Action verbs also include speech acts. Perceptive verbs have the subject as experiencer, such as $r a \Leftrightarrow p f a N$ 'to listen'. Cognitive verbs report psychological or emotional events in which the subject is experiencer, as in $r u \Leftrightarrow u c a \prod_{k}$ 'to know'. Descriptive verbs describe temporal settings. And contingencies are happenings in which the subject is patient. They take place without plan or volition, as in thanthiithilli

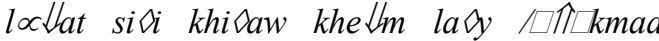

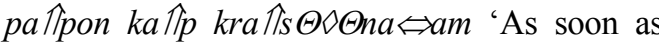
the dark green blood flew out to blend with the current.'
} 
Diagram 2: A salience scheme of time adverbial clause for Thai travelogue discourse

\begin{tabular}{|c|c|}
\hline Band 1 & Post-posed time adverbial clause \\
\hline \multirow[t]{3}{*}{ Storyline } & Motion \\
\hline & Action \\
\hline & Perception/Cognition/Description ${ }^{3} /$ Contingencies \\
\hline Band 2 & Pre-posed adverbial clause \\
\hline \multirow[t]{3}{*}{ Background } & Motion \\
\hline & Action \\
\hline & Perception/Cognition/Description/Contingencies \\
\hline Band 3 & Pre-posed adverbial clause \\
\hline Setting & $m \propto \Downarrow_{a}$ 'when', la $\diamond N c a \Uparrow a k$ 'after'+ Descriptive verb \\
\hline Band 4 & Pre-posed adverbial clause \\
\hline Irrealis (Preview) & $k \square \hat{\Uparrow} \square n$ 'before' + motion \\
\hline & Action/Cognition/Contingencies \\
\hline Band 5 & Pre-posed adverbial clause \\
\hline Cohesion & Cohesion between successive paragraphs \\
\hline & Cohesion within paragraphs \\
\hline
\end{tabular}

\section{Abbreviations}

ASP perfective aspect marker

CLS classifier

FP final particle

PASS passive marker

\section{References}

Burusphat, Somsonge. 1991. The Structure of Thai Narrative. Summer Institute of Linguistics and the University of Texas at Arlington publications in Linguistics 98. Dallas: Summer Institute of Linguistics and the University of Texas at Arlington.

Givo $\Leftrightarrow$ n, Talmy. 1990. Syntax: A Functional-Typological Introduction.

\footnotetext{
${ }^{3}$ Note that post-posed time adverbial clause containing a descriptive verb can advance the storyline as it is reporting a main event (see example 5).
}

Amsterdam/ Philadelphia: John Benjamins Publishing Company.

Grimes, Joseph E. 1975. The Thread of Discourse. The Hague: Mouton.

Hopper, Paul. 1979. Aspect and Foregrounding in Discourse. In Syntax and Semantics 12: Discourse and Syntax, ed. by Talmy Givo $\Leftrightarrow \mathrm{n}$, pp. 213-241. New York: Academic Press.

Hopper, Paul J. 1995. The Category of 'event' in Natural Discourse and Logic. In Discourse Grammar and Typology: Paper in Honor of John W.M. Verhaar, ed. by Werner Abraham et.al. Amsterdam: John Benjamins. 
Hopper, Paul and Sandra Thompson. 1980.

Transitivity in Grammar and

Discourse. Language 56: 251-299.

Jones, Larry B. and Linda K. Jones. 1979. Multiple levels of information in discourse. In Discourse Studies in Mesoamerican Languages 1: Discussion, ed. by Linda K. Jones, pp. 3-28. Summer Institute of Linguistics Publications in Linguistics 58. Dallas: Summer Institute of Linguistics and the University of Texas at Arlington.

Longacre, Robert E. 1989. Two Hypotheses Regarding Text Generation and Analysis. Discourse Processes 12: 413460.

Longacre, Robert E. 1996. The Grammar of Discourse. Second Edition. New York and London: Plenum Press.

Thompson, Sandra and Robert Longacre. 1985. Adverbial clauses. In Language Typology and Syntactic Description 2: Complex Constructions, ed. by Timothy Shopen, pp. 171-233. Cambridge: Cambridge University Press. 